\title{
Violência na tragédia grega: infanticídios e parricídios
}

\author{
Tereza Virgínia Ribeiro Barbosa \\ Universidade Federal de Minas Gerais \\ virginiarb@yahoo.com.br
}

Pois na verdade nada há de mais miserável que o homem De todos os seres que vivem e rastejam em cima da terra.

Ilíada XVII, 446-447

ABSTRACT: This article deals with different manifestations of violence, including the distortions and mistakes that maternal or other kind of love can produce on the object of its affections. In order to reflect about this theme, we focus on some ancients sources, such as Plutarch's Of the affection towards offspring, mythological narratives and excerpts of Greek tragedies. To understand some aspects of the dynamics of good and evil, we recur to the thought of the French philosopher Paul Ricoeur.

KEYWORDS: maternity; violence; Plutarch; tragedy; Ricoeur.

Eis nosso programa: começamos por falar sobre os descuidados zelos, sobre ternuras tresloucadas no seio familiar. Buscamos a violência que condena a família, aquela potência guardada em casa que o teatro grego exibe explicitamente; a brutalidade social materializada como fato histórico na cena, abordando os casos de algumas mães que praticaram crimes violentos contra suas próprias crianças. O tema é filicídio, violência e tragédia.

O percurso não será demasiado grande; no mesmo lugar habitam as doçuras e amarguras. $\mathrm{O}$ mesmo espaço que protege tiraniza. $\mathrm{O}$ tema que focalizamos - da forma como o enxergamos - não se limita ao mundo antigo, nem aos países menos desenvolvidos. Gerardine Meaney $^{2}$ e David Konstan ${ }^{3}$ dão prova disso. Os investigadores mencionados desenvolvem pesquisas que, pontualmente, resultaram em dois interessantes artigos sobre o assunto. Meaney retrata o cânone da literatura dramática irlandesa atual a partir da difícil relação entre pais e filhos, pautada, na Irlanda, pelo mito de Édipo. Para ela o teatro irlandês discute, ritualiza e restabelece tensões domésticas naturais. David Konstan, por seu lado, está mais preocupado com o

\footnotetext{
${ }^{1}$ Na tradução de Frederico Lourenço (cf. Homero. Odisseia. Tradução de Frederico Lourenço. Lisboa: Edições Cotovia, 2003), a fala está na boca de Zeus, o qual, ao contemplar os cavalos imortais de Aquiles que choram pela morte de Pátroclo, lamenta os animais.

${ }^{2}$ Cf. Meaney, G. The sons of Cuchulainn: violence, the family, and the Irish canon. Éire-Ireland. Morristown, vol. XLI, n. 1/ 2, p. 242-261, 2006.

${ }^{3}$ Cf. Konstan, D. Anger, hatred, and genocide in ancient Greece. Common knowledge. Durham, vol. XIII, n. 1, p. 170-187, 2007.
} 


\section{nuntius antiquus}

aspecto macro da questão. Investigando guerras, ele examina a cólera e o ódio no mundo antigo e no mundo contemporâneo. Nenhum deles, no entanto, execra o sentimento violento de extermínio que gera algumas das mais decisivas moções coletivas contra um grupo ou indivíduo específico. Outro estudioso que parece seguir o mesmo caminho, David Cohen, em obra de 1995, aponta para a assunção de que a violência faz parte do humano. Amaldiçoá-la é amaldiçoar nossa própria natureza. Concordamos com Cohen ${ }^{4}$ quando ele afirma que conflito e disputa, sobretudo numa cultura agonística como a grega, são componentes normais da vida em sociedade. Cabe a nós entender seu papel, decifrar os enigmas das emoções misturadas que geram as ações humanas; apreciar as tensões e contradições que, na verdade, contribuem para mudanças vantajosas e promovem uma complexidade e dinamismo capazes de manter vivo o sistema social. ${ }^{5}$

Perguntamos, todavia: que ternura há maior que a de uma mãe para com seu filho? Que cuidado mais desinteressado pode haver? Violência contranatura seria aquela de uma mãe que extirpasse os próprios rebentos. Neste ponto, contudo, contradizendo o senso comum, saltam furiosas à nossa mente não só as terríveis e cotidianas notícias de jornal como também todas as velhas e antigas Medeias: a de Eurípides, a de Sêneca, a de Ovídio... lançam-se como cadelas a nos morder. Tríade terrível de desamor. Não. Medeia, por agora, será horizonte longínquo para nós.

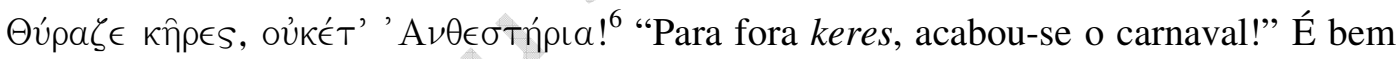
possível, porém, que no trajeto encontremo-nos com ela e com Jasão e que recordemos Agamêmnon e Hécuba. Não obstante, confessamos; diante de tantas opções, fomos arrebatados pela figura de Jocasta e sobre ela deitaremos nosso olhar. Falemos não da personagem de Sófocles, mas a de Fenícias, com sua suave violência... Mal ou bem? Tudo misturado, tudo confundido, $\mu i ́ \gamma \nu v \mu \iota$ !

Vamos, portanto, contemplar transgressões que surgem a partir da incapacidade de distinguir objetivamente sentimentos que podem ser tanto egoístas quanto altruístas

\footnotetext{
${ }^{4}$ Cf. Cohen, D. Law, violence, and community in classical Athens. Cambridge/ New York: Cambridge University Press, 2000, p. 5.

${ }^{5}$ Cf. Cohen, op. cit., p. 12.

${ }^{6}$ Cf. Rose, H. J. Keres and Lemures. The Harvard Theological Review. Cambridge, vol. XLI, n. 4, 1948, p. 217. O autor escreve um artigo inteiro sobre essa velha fórmula litúrgica, à qual equivale o ludo de Guimarães Rosa, no Grande Sertão, ao aportuguesar a expressão latina uade retro. O escritor, em trocadilho, substitui a tradução original, que seria "recuai", "ide para trás" para um coloquial vá de retro (vá de fasto, vá andando de costas). O trecho de Guimarães Rosa (cf. Rosa, J. G. Grande Sertão: veredas. Rio de Janeiro: José Olympio, 1976, p. 260) a que nos referimos: "Vá de retro! - nanje os dias e as noites não recordo".
} 


\section{nuntius antiquus}

ou mesmo ambos simultaneamente. E, para falar de misturas entre bem e mal, tomamos um trecho de Plutarco, retirado do seu pequeno tratado intitulado Do cuidado com a prole. Citamos. Trata-se de excerto retirado do capítulo $3:{ }^{7}$

Pois nada é tão inacabado, tão sem recurso, tão nu, tão disforme e manchado quanto o homem quando o vemos ao nascer. Talvez o único a quem a natureza não deu um caminho limpo para a luz; mas, empapado no sangue e repleto de sebo, é mais semelhante a um assassinado que a um nascido e é de ninguém tocar, nem abraçar, nem prender, nem envolver exceto a uma que - naturalmente - ama.

Que agudeza de raciocínio! É verdade: qualquer ser humano, mesmo que tenha uma boa herança (seja biológica, seja de bens materiais), nasce desprovido, sujo e repulsivo. Aliás, digamos de passagem: nada é mais violento que um parto dito natural. Pois bem, sem recursos para crescer em plenitude, sabedoria e graça, o homem necessita de cuidados. Não lhe basta nascer com capacidades, nem são suficientes as condições sociais ou financeiras que o mundo lhe pode dar (ou tomar). Sua vulnerabilidade é enorme, do nascer ao morrer. Por isso a natureza providenciou-lhe uma protetora. Nosso ponto, entretanto, será: o que ocorre e o que fazer quando a mãe não cuida da prole? Resta apelar para Týche e perguntar-lhe a cada instante, com aflição: "Qual o melhor caminho?".

Mas observe-se: a pergunta assim formulada, com o adjetivo "melhor" a modificar o substantivo "caminho", introduz limites hierárquicos de qualidade, de valores, de vantagem e conveniência, que nos levariam inevitavelmente a problemas existenciais complicados, quiçá insolúveis. A condição imposta pela questão nos faz pensar na palavra grega aporía, pois são inúmeros os caminhos e curto o tempo para os achar. Felizmente (ou infelizmente), porém, o comum dos mortais tem uma mãe para guiá-los, exceto em casos de abandono, rejeição ou outras impossibilidades práticas (trabalho, morte, viagem etc.). E cremos que essa foi a grande questão de Agamêmnon, Édipo, Medeia e todas as máscaras trágicas que encobriram as faces de Ésquilo, Sófocles e Eurípides.

Todavia, estaria mesmo o ser humano - brotós ou thnetós - mergulhado em possibilidades mil, detalhes sutis e variantes mínimas a confundi-lo e desnorteá-lo? Será

7 Cf. Plutarco, Do cuidado com a prole, 496b (acima, citado em minha tradução):

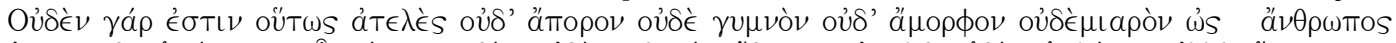

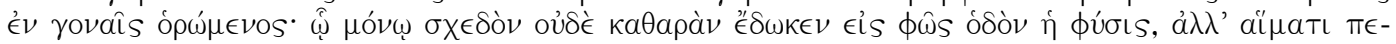

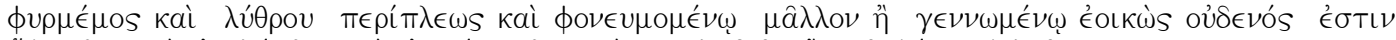

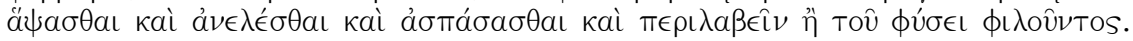


que todo o mal para o homem se dá por vontade alheia? Ora, Ésquilo, em Persas, pergunta: “... Da dolosa fraude de um deus, que homem - mortal - escapa?! Qual o regente que num passo ágil - de um salto - é feliz? Pois Ilusão, amiga e sedutora, atrai o vivente para redes de onde não é dado a um mortal escapar ileso". ${ }^{8}$ Um beco sem saída? Tema de tragédia, isso sim... O Zeus épico, com efeito, resolveria de forma mais simples o drama; ele diria:
Vede bem como os mortais acusam os deuses!
De nós (dizem) provêm as desgraças, quando são eles,
Pela sua loucura, que sofrem mais do que deviam! ${ }^{9}$

E Zeus tem razão! De nossa parte, ao menos, concordamos com ele e não queremos nos ver, ou, em outros termos, não queremos considerar os mortais como desvalidos, vítimas trágicas de um deus ou de um cosmo cruel. Todavia como conciliar a epígrafe escolhida ("nada há de mais miserável que o homem...") com esse desabafo do deus dos raios e trovões? Se o homem é, mesmo, a mais miserável e vulnerável de todas as criaturas, a quem culpar por tal desgraça se ela não é de responsabilidade dos deuses? Talvez o problema se resolvesse com o uso da inteligência, da razão e com o estabelecimento de uma ética.

Neste caso a cultura vem em nosso socorro. Estabelece normas. Impõe leis. Divide as muitas possibilidades em caminhos do bem e do mal. Reduz as opções, limitando-as a duas apenas. Isto ou aquilo. O certo e o errado.

Contudo a coisa não é simples... Bem e Mal se confundem às vezes; na tragédia, quase sempre. Mal para quem? E o mesmo diremos do bem; bem para quem? Afinal, segundo Rueschemeyer apud Cohen, “[t]odas as formas de ação social bem como todos os componentes de instituições sociais têm múltiplas e contrastantes consequências que se mantêm em aguda tensão umas com as outras". ${ }^{10}$ Ao que parece, Aristóteles ${ }^{11}$ está certo: o homem, quando perfeito, é a melhor das criaturas, mas quando se afasta do bem

\footnotetext{
${ }^{8}$ Cf. Ésquilo, Persas, 93-101 (acima, citado em minha tradução):

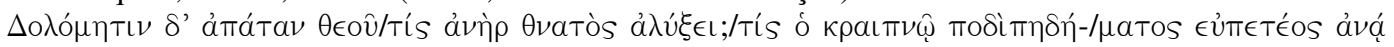

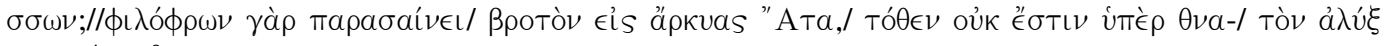

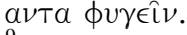

${ }^{9}$ Cf. Odisseia I, 32-34 (aqui, citada em tradução de Frederico Lourenço):

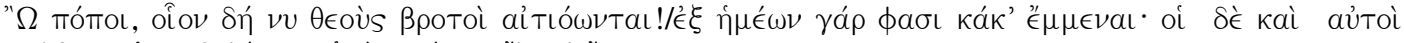

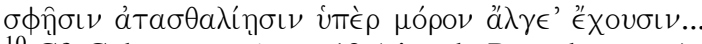

${ }^{10}$ Cf. Cohen, op. cit., p. 12 (citando Rueschemeyer): All forms of social action as well as components of social institutions have multiple and opposing consequences that stand in pervasive tension with each other.

${ }^{11}$ Cf. Política 1253a.

134
} 
- completamos o filósofo - quando tende para o mal, nesta circunstância ele é o pior dos seres, o que de fato significa que ele é perfeito em ser mau.

Pensemos então: e se alguém elegesse o caminho pior, antes, o caminho "do" mal, e gostasse dele? Que será de quem faz tal escolha? Será um úßpı transgressor? Um monstro? Ou um herói?

Ao agir assim, seremos marginais vivendo na paralegalidade - dormindo com a mãe, eis Édipo (ou com o pai, caso de Mirra, ${ }^{12}$ ou com a filha, o de Tiestes...), expondo e eliminando filhos nascidos como Creúsa, Filomela, Cronos? Banqueteando-nos com as tenras carnes de criancinhas como Tântalo ${ }^{13}$ e Licáon, o homem que Zeus transforma em lobo, ${ }^{14}$ ou comendo os próprios filhos tal qual o já mencionado Tiestes? Seremos assassinos vitoriosos e vigorosos que, almejando cumprir nosso desejo mais particular (ou cedendo à criminalidade sem regras?), rompemos limites, entraves, quebramos pactos antes estabelecidos, exercemos o poder que emana da paixão e saímos fulgurantes num carro do sol? Isso mesmo; não há dúvida de que tal atitude nos fará pelo menos autênticos como Medeia, que ponderou, deliberou e, racionalmente, encontrou para si o melhor caminho: fez-se deusa, colocou-se acima do bem e do mal; matou os filhos e saiu gloriosa escarnecendo Jasão.

Sob tais aspectos, em uma ótica revanchista, essa é uma boa opção. Intensificar a natureza humana, torná-la mais violenta que a dos outros equivale a voltar-se contra a própria natureza humana e tornar-se sobre-humano (ou subumano?). Exemplos desse anseio não faltam desde Homero. Vejam no Canto XXI da Ilíada, nos versos 12-22; 21 33, o feito de um dos mais célebres guerreiros gregos:

(...) o herói gerado por Zeus deixou a lança na ribeira, Inclinada contra um tamarindo, e mergulhou como um deus, Segurando apenas a espada: planeava no espírito trabalhos ruins. Pôs-se a dar golpes com a espada, às voltas no rio. Surgiram gritos Pavorosos dos que ele feria; a água ficou vermelha de sangue.

\footnotetext{
${ }^{12}$ Sobre Mirra, cf. Ovídio, Metamorfoses X, 298ss.

${ }^{13}$ Segundo Píndaro (cf. Olímpica I, 60), Tântalo serviu Pélope como comida para os deuses.

${ }^{14}$ Herói muito antigo, do tempo em que deuses e homens sentavam-se a uma só mesa (cf. Hesíodo, Trabalhos e Dias, 109; Píndaro, Olímpica I, 54), Licáon é filho de Pelasgo (o primeiro homem do mundo) e da ninfa Cilene (algumas vezes, aparece sendo filho de Melibeia, outras de Dejanira). Em Ovídio (cf. Metamorfoses I, 218), Licáon nasce do sangue dos gigantes mortos na Gigantomaquia. Como rei da Arcádia, tendo Zeus por hóspede, após a sedução de sua filha pelo pai de todos os deuses, Licáon serve, num banquete, ao deus, o filho gerado no ato da sedução da jovem Arcas. Enfurecido, Zeus vira a mesa, destrói a casa e transforma Licáon em lobo. Depois, revive Arcas e entrega-o a pastores (cf. Irving, P. M. C. F. Metamorphosis in Greek myths. Oxford: University Press, 1992, p. 216); cf ainda Apolodoro 3.8.1.
} 
(...)

E Aquiles, quando se fartou

Da matança, tirou do rio doze mancebos:

O preço do morto Pátroclo, filho de Menécio.

Levou-os de lá, assarapantados como gamos,

E atou-lhes as mãos atrás com as belas correias

Que eles traziam como adereços nas túnicas bem tecidas,

E deu-os aos amigos para os levarem para as naus recurvas.

Depois lançou-se de novo, ávido de mais morticínio.

Como afirma Konstan, “[h]oje o massacre de populações inteiras é considerado uma ofensa contra os direitos humanos e contra as leis (...) Visto de fora, [os que cometem tais atos] são julgados como bárbaros em excesso", são demonizados. ${ }^{15}$

Não é, entretanto, desta forma que percebemos Aquiles. Caçador e predador incansável, o violento filho de Tétis, no decorrer da chacina que enfurece o rio Xanto, com zelo e diligência separa doze jovens para serem queimados em honra de Pátroclo, seu amigo morto por Heitor. Quanta violência e quanta ternura ao mesmo tempo! Margo Kitts ${ }^{16}$ associa o episódio com a prática da caçada ritual, conforme teoria desenvolvida por Walter Burkert. ${ }^{17}$ Kitts todavia conclui que "o episódio não é histórico, é poético" ${ }^{18}$ Contudo, Burkert, já no primeiro capítulo de seu Homo Necans, aborda o sacrifício como a ritualização do ato de matar e afirma: “Agressão e violência humana marcaram o progresso de nossa civilização; elas parecem, com certeza, terem se desenvolvido tanto que durante seu curso tornaram-se o problema central do presente". E ainda: "Mais coisas podem ser ditas em favor da tese de que todas as ordens e formas de autoridade na sociedade humana foram fundadas na institucionalização da violência”. (...) E "todas", para o estudioso alemão, abrange inclusive - e sobretudo - a religião. Para ele, "[o] assassinato sacrificial é a experiência básica do sagrado". Burkert afirma também, que, "graças às descrições em Homero e na tragédia, (...) podemos reconstruir o percurso de sacrifícios ordinários dos gregos para os deuses olímpicos quase que em sua totalidade". ${ }^{19}$

\footnotetext{
${ }^{15}$ Cf. Konstan, op. cit., p. 170: Today, the slaughter (massacre) of whole populations is regarded as an offense against human rights and against the laws (...). From outside, they are judged as barbarous excesses (...).

${ }^{16}$ Cf. Kitts, M. The sacrifice of Lykaon. Metis. Anthropologie des mondes grecs anciens. Paris, vol. VII, n. 1, p. 161, 1992.

${ }^{17}$ Burkert, W. Homo Necans: the anthropology of Ancient Greek sacrificial ritual and myth. Translated by Peter Bing. Berkeley/ Los Angeles/ London: University of California Press, 1983, p. 3.

${ }^{18}$ Cf. Kitts, op. cit., p. 170: But the episode is not historical; it is poetic.

${ }^{19}$ Cf. Burkert, op. cit., p. 1 e 3: Aggression and human violence have marked the progress of our civilization and appear, indeed, to have grown so during its course that they have become a central problem of the present. (...) More can be said for the thesis that all orders and forms of authority in 136
} 
Mas o fato de lidarmos com a poesia - embora se saiba que sacrifícios humanos existiram - é um alento. Ele permite que possamos perceber a ternura e o afeto existentes na violência. E essa é nossa temática aqui. Lidamos com poesia para falar da miserabilidade (e grandiosidade!) do humano. Para falar de crimes gloriosos e vítimas miseráveis. Porque entendemos, como Iser, ${ }^{20}$ que há no texto ficcional muita realidade que não só deve ser identificável como realidade social, mas que também pode ser identificada como realidade de ordem sentimental e emocional. "Estas realidades, por certo diversas, não são ficções, nem tampouco se transformam em tais pelo fato de estarem na apresentação de textos ficcionais”. Medeias, Jasões, Agamêmnons, Hécubas existem; sabemos disso, as manchetes televisivas (e da internet) de cada dia e - sem glamour, é bem verdade - e também as matérias jornalísticas provam-no. É possível ver no inventado muito da realidade social que ocorre à nossa volta e a dor que se manifesta em nós diante dessas coisas é por isso inegável. Neste sentido, os infanticídios vistos no teatro têm materialização em nosso corpo. Experimentamos emoções, contemplamos ações praticadas sob estes páthoi e temos tempo para refletir e optar...

Olhemos, sem embargo, a doce viúva de Laio. Ela foi, no mínimo, descuidada: engravidou e gerou um fruto que, proibido, não foi abortado. Terá agido bem? Salvou ou condenou a vida poupada? Que pensar sobre a vida preservada de Édipo?

Devemos por certo buscar a origem da desgraça do bom rei-menino, abandonado, pés transpassados, no monte Citerão. Sim; como juízes implacáveis, busquemos o primeiro a cometer o crime. O primeiro, que, em termos do criminoso de Foucault, ${ }^{21}$ teria rompido o pacto. $\mathrm{O}$ criminoso não é outro senão Laio! Ele poderia ser acusado do crime de abdução de Crisipo. ${ }^{22} \mathrm{Na}$ peça de Eurípides, porém, não se trata

human society are founded on institutionalized violence. (...) Sacrificial killing is the basic experience of the "sacred". (...) Thanks to the descriptions in Homer and tragedy, we can reconstruct the curse of an ordinary Greek sacrifice to the Olympian gods almost in its entirety.

${ }^{20} \mathrm{Cf}$. Iser, W. Os atos de fingir ou o que é fictício no texto ficcional. In: Costa Lima, L. (org.). Teoria da literatura em suas fontes. Rio de Janeiro: Civilização Brasileira, 2002. Vol. II, p. 958.

${ }^{21}$ Cf. Foucault, M. Os anormais. Tradução de Eduardo Brandão. São Paulo: Martins Fontes, 2002, p. 117.

${ }^{22}$ Cf. Cohen, op. cit., p. 156-158: A widely accepted view of Athenian paederasty maintains that there was no legal prohibition against unremunerated consensual sexual intercourse in which an adult took the active role and an Athenian youth played the passive partner. Some scholars have gone further and maintained that there was also absolutely no social sanction directed at such behavior provided that the relationship was not perceived as mercenary or promiscuous. Such discussions, however, overlook an important aspect of paederastic intercourse. This aspect arises from the potentially problematic nature of the consent by which the younger partner permits the older man to use him sexually. In Athenian law, as in most other ancient and modern legal systems, young males of an age to attract paederastic courtship, that is, conventionally, before the growth of the first beard, are legal minors. That is, they are incapable of entering into legal transactions, and are in principle completely subject to the authority of their fathers. In the absence of paternal authority their affairs are managed by a guardian until they come of 
disso. No momento da peça, pela necessidade de buscar o oráculo, seu crime maior é ser improdutivo, ser estéril. Ele é quem, por muito tempo, dormiu com Jocasta sem plantar nela filhos. Ocorre que Laio, depois da proibição formal de Febo, quiçá tomado pelo descuido, semeou a semente outra vez no ventre da esposa e ela concebeu. Ela própria, em Fenícias, informa que Apolo tinha dito: "Senhor da Tebas dos luzentes corcéis, não lances semente no sulco da vida contra a vontade celeste. Se gerares um filho, o gerado te matará e toda a tua casa perecerá num abismo de sangue”. Mas “(...) ébrio de prazer, na loucura de Baco, Laio plantou um filho..."23 Culpado! Culpado?! O que foi feito de sua esterilidade?! Como concebeu Jocasta depois de tantos anos? Sófocles, perplexo diante do mistério, se calou, mas Eurípides, na opinião de Swift, acusa: Laio "deixou-se levar pelo prazer físico num momento de irracionalidade" e preferiu a luxúria. ${ }^{24}$ Konstan, ${ }^{25}$ todavia, contrapõe que "[e]moções, para os gregos, não são simplesmente afecções opostas à razão. (...) Emoções dependem essencialmente de julgamentos.”.

A cálida Jocasta levou a gravidez até o fim. Desarmada, descuidada, quase inocentemente, deixou o menino ver a luz. Nasceu sujo de sangue e, talvez por isso, o pai se lembrou de Apolo: "Reconheceu o erro. Ordenou, então, a pastores exporem a criança nos prados de Hera (...)"26 e daí em diante, queridos, a tragédia continua. Vem a

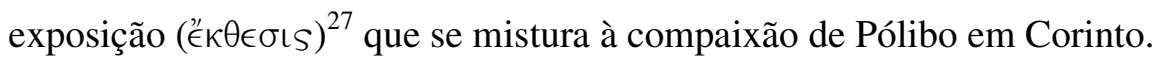

Reflitamos: devia Laio não ter semeado? Por que, se sua semente não havia fecundado Jocasta antes? Cabia a esta, por outro lado, matar, antes, a semente? Ou os

age. Further, most legal systems carry over this legal incapacity into the sphere of sexuality regulated by the criminal law, viewing children below a certain age as incapable of consenting to sexual intercourse or entering into marriage without their father's consent. This incapacity for legal consent renders as rape what might otherwise have been seduction.

${ }^{23}$ Cf. Eurípides. As Fenícias. Tradução de Donaldo Schüler. Porto Alegre: L\&PM Pocket, 2005, v. 17-20/ 21-22.

${ }^{24}$ Cf. Swift, L. A. Sexual and familial distortion in Euripides' Phoenissae. Transactions of the American Philological Association. Baltimore, vol. CXXXIX, n. 1, 2009, p. 56.

${ }^{25}$ Cf. Konstan, op. cit., p. 177: Emotions, for the Greeks, were not simply opposed to reason (...) emotions depend essentially on judgments.

${ }^{26}$ Cf. Eurípides, op. cit., v. 23-25.

27 A ë $\Theta \theta \in \sigma$ เS é prática comum no mundo antigo. Inúmeras narrativas seguem o seguinte roteiro: uma criança é concebida de forma ilegítima ou em situações pouco usuais; sua mãe é de posição social elevada; o pai é deus ou estrangeiro; existem possíveis evidências da reprovação dos deuses; a criança é abandonada; criada por animais ou pastores ou divindades que a nutrem de forma maravilhosa para que sobreviva; sobrevivente, ela é adotada por um casal sem filhos e quando crescida mostra-se pessoa de valor extremado. Essas etapas estão registradas na obra de Huys (The tale of the hero who was exposed at birth in Euripidean tragedy: a study of motifs. Symbolae Facultatis Litterarum Lovaniensis, Series A 20. Leuven: University Press Leuven, 1995, p. 27). Toda a obra do pesquisador belga é dedicada à prática da exposição na Antiguidade, mais especificamente nas tragédias de Eurípides. 


\section{nuntius antiquus}

deuses descuidados com a grei humana resolveram vingar seu deslize? E Zeus disse antes que os deuses não tinham culpa...

Contudo, se retomarmos Plutarco, recordam-se? "Ao gerado que nasce a natureza não deu um caminho limpo para a luz, mas, empapado no sangue, é mais semelhante a um assassinado que a um nascido e é de ninguém tocar, nem abraçar, nem prender, nem envolver exceto a uma que - naturalmente - ama”. Ora, pensamos, qual o filho que, aos poucos, devagar, não suga as forças e vidas de seus pais até que eles, envelhecidos, deixem o governo da casa para sua prole? Talvez a promessa amedrontadora fosse, afinal, aplicável a todos os gerados (o que quer dizer, a cada homem, num ciclo infinito de geração e destruição). Metáforas literárias. Oráculos malentendidos.

Face a tudo, endossamos a opinião de Paul Ricoeur, em sua conferência $O$ escândalo do mal, de 1982. O mal que fazemos, o mal que sofremos não se explica por um pecado, digo, um crime original. Vamos desmitologizar a vida; coloquemos as coisas em termos práticos, uma vez que, enumerando suas importantes reflexões, temos que: “...o mito, não mais que ele, em sua indistinção entre o ethos e o cosmos, não distingue entre o bem e o mal", ele coloca a fonte de todas as coisas "além do bem e do mal"; "obriga, diante de todo problema, a pensar em termos de origem": origem de todas as coisas, origem do bem e do mal; "próprio do mito, portanto, é arrastar-nos para trás, enquanto nosso problema diante do mal é, se [podemos nos atrever a dizer], pensar à frente, para o futuro". 28

No caso específico de Jocasta, convido-os a refletir sobre a medida tomada para não matar o menino nascido: os pais abandonaram a criança; nos termos mais delicados de Huys, o infante foi exilado. O ato definitivo não foi praticado. Tivemos, no entanto, requintes de crueldade. Édipo não foi abandonado à porta de um santuário, como Íon. Deixaram-no em lugar distante, de pouco acesso, longe, frio e agreste. Dificilmente o infeliz seria recolhido. Recém-nascido, não se deram ao trabalho de aconchegá-lo em cesto, antes lhe foram perfurados e atados os pés. Concordamos com Huys: a ék $\theta \in \sigma ı s$ é a mais terrível etapa da vida dos infantes heróis. Seja para evitar o cumprimento de uma

${ }^{28}$ Cf. Ricoeur, P. Le scandale du mal. Esprit. Paris, n. 7-8, p. 2, julho de 1988 (disponível em: $<$ http://www.esprit.presse.fr/ review/article.php?code=7737> acesso em: 5 fev. 2010): ... Le mythe, pas plus qu'il ne distingue entre l'éthos et le cosmos, ne distingue entre le bien et le mal; la source de toutes choses est plutôt placée au-delà du bien et du mal; le mythe contraint, face à tout problème, à penser en termes d'origine: origine de toutes choses, origine du bien et du mal; le propre du mythe, dès lors, c'est de nous tirer en arrière, alors que notre problème face au mal est de penser, si j'ose dire, en avant, vers le futur. 


\section{nuntius antiquus}

profecia, seja por rejeição à fecundação violenta, o abandono é ação grave. Mas, mesmo assim, o ato definitivo não foi levado às últimas consequências. Seus genitores deixaram possibilidades de salvação. Não olhemos o passado, sigamos os conselhos de Ricoeur. Fatores outros repararam o mal perpetrado. Poderíamos culpabilizar, condenar, punir; tenhamos, porém uma postura mais otimista: a é $\kappa \theta \in \sigma \iota s$ é etapa importantíssima que prepara a criança para enfrentar as forças mais adversas que contra ela virão no futuro. $^{29}$ As culpabilidades aprisionadoras limitam, sufocam. ${ }^{30}$ Neste sentido, se seguimos Ricoeur, refiro-me à conferência mencionada, há que se enfrentar o mal "apesar de" tudo o que bloqueie o futuro. A poesia pode às vezes iluminar o impasse, pois ela tece em torno do nó e da aporia. Ficamos, à guisa de argumento conclusivo, com Guimarães Rosa, em Grande Sertão: "Alto eu disse, no me despedir: - Minha Senhora Dona: um menino nasceu - o mundo tornou a começar!...” - e saí para as luas. “(...) o amor dá as costas a toda reprovação".31

Finalmente: o sofrimento humano, sua origem; o mal que grassa entre nós, sua origem; para gregos e troianos, tudo isso é mistério e a única forma de enfrentar esses monstros é com o afeto. Se não o de mãe, ao menos o afeto daquele que acolhe e olha para o futuro, apesar de tudo.

\section{Referências}

BURKERT, W. Homo Necans: the anthropology of Ancient Greek sacrificial ritual and myth. Translated by Peter Bing. Berkeley/ Los Angeles/ London: University of California Press, 1983.

COHEN, D. Law, violence, and community in classical Athens. Cambridge/ New York: Cambridge University Press, 2000.

\footnotetext{
${ }^{29}$ Cf. Huys, op. cit., p. 27-39.

30 Reflexões semelhantes são desenvolvidas poeticamente por Bertolt Brecht, na balada "Von der Kindesmörderin Marie Farrar" ("Da infanticida Marie Farrar"), em que o escritor, no refrão, exorta os ouvintes à misericórdia e ao não julgamento: Doch ihr, ich bitte euch, wollt nicht in Zorn verfallen/ Denn alle Kreatur braucht Hilf von allen (em tradução livre: "Não vos indigneis/ toda criatura precisa da ajuda de todos"). Vale conferir ainda a montagem do grupo "Julietas e os Metabonecos" (http://www.youtube.com/watch?v=kYK38BZthdM) e o filme "Subterrâneo", de estudantes da pósgraduação (disciplina "Imagem em Movimento", ministrada por Rosa Berardo) da Universidade Federal de Goiânia (http://www.youtube.com/watch?v=tbzN1TZBdEE\&feature=related).

${ }^{31}$ Cf. Rosa, op. cit., p. 353. 
EURIPIDES. Phoenissae. Ed., intr. and com. of Donald J. Mastronarde. Cambridge: University Press, 1994.

. As Fenícias. Introdução, tradução e notas de Manuel dos Santos Alves. Coimbra: Instituto de Alta Cultura, 1975.

As Fenícias. Tradução de Donaldo Schüler. Porto Alegre: L\&PM Pocket, 2005.

FOUCAULT, M. Os anormais. Tradução de Eduardo Brandão. São Paulo: Martins Fontes, 2002.

HOMERO. Odisseia. Tradução de Frederico Lourenço. Lisboa: Edições Cotovia, 2003.

. Odyssey of Homer. Introd. and com. W. B. Stanford. London: St. Martin Press, 1987. Vol. I.

. Iliadis. Oxford: University Press, 1989. Tome I/ II.

. Ilíada. Tradução de Frederico Lourenço. Lisboa: Edições Cotovia, 2005.

HUYS, M. The tale of the hero who was exposed at birth in Euripidean tragedy: a study of motifs. Symbolae Facultatis Litterarum Lovaniensis, Series A 20. Leuven: University Press Leuven, 1995.

IRVING, P. M. C. F. Metamorphosis in Greek myths. Oxford: University Press, 1992.

ISER, W. Os atos de fingir ou o que é fictício no texto ficcional. In: COSTA LIMA, Luiz (org.). Teoria da literatura em suas fontes. Rio de Janeiro: Civilização Brasileira, 2002. Vol. II, p. 957-987.

KITTS, M. The Sacrifice of Lykaon. Metis. Anthropologie des mondes grecs anciens. Paris, vol. VII, n. 1, p. 161-176, 1992.

KONSTAN, D. Anger, hatred, and genocide in ancient Greece. Common knowledge. Durham, vol. XIII, n. 1, p. 170-187, 2007.

MEANEY, G. The sons of Cuchulainn: violence, the family, and the Irish canon. EireIreland. Morristown, vol. XLI, n. 1/ 2, p. 242-261, 2006.

NUSSBAUM, M. C. A fragilidade da bondade. Tradução de Ana Aguiar Cotrim. São Paulo: Martins Fontes, 2009. 
PLUTARQUE. De l'amour de la progéniture. Texte établi par Jean Dumortier et Jean Defradas. Paris: Les Belles Lettres, 1975.

RICOEUR, P. Le scandale du mal. Esprit. Paris, n. 7-8, p. 57-63, julho de 1988 (disponível em http://www.esprit.presse.fr/ review/article.php?code=7737 acesso em 5 de fevereiro de 2010).

Introducción a la simbólica del mal. Buenos Aires: Asociación Editorial La Aurora, 1976.

ROSA, J. G. Grande Sertão: veredas. Rio de Janeiro: José Olympio, 1976.

ROSE, H. J. Keres and Lemures. The Harvard Theological Review. Cambridge, vol. XLI, n. 4, p. 217-228, 1948.

SWIFT, L. A. Sexual and familial distortion in Euripides' "Phoenissae". Transactions of the American Philological Association. Baltimore, vol. CXXXIX, n. 1, p. 53-87, 2009.

WISE, J. Tragedy as "an augury of a happy life". Arethusa. Baltimore, vol. XLI, n. 3, p. 381-410, 2008. 